TITLE: Clarity in Reporting Terminology and Definitions of Set End Points in Resistance Training

RUNNING TITLE: Resistance Training End Points

AUTHORS: James Steele Ph.D ${ }^{\mathrm{a}}$, James Fisher $\mathrm{MSc}^{\mathrm{a}}$, Jürgen Giessing Ph.D ${ }^{\mathrm{b}}$, Paulo Gentil Ph. $\mathrm{D}^{\mathrm{c}}$

AUTHOR AFFILIATIONS: ${ }^{\text {a} C e n t r e ~ f o r ~ H e a l t h, ~ E x e r c i s e, ~ a n d ~ S p o r t ~ S c i e n c e, ~ S c h o o l ~ o f ~}$ Sport, Health and Social Sciences, Southampton Solent University, UK, ${ }^{\mathrm{b}}$ Institute of Sport Science, University of Koblenz-Landau, Germany, ${ }^{c}$ Federal University of Goias, Faculty of Physical Education and Dance, Brazil

\title{
CONTACT AUTHOR:
}

James Steele (james.steele@solent.ac.uk)

Centre for Health Exercise and Sport Science,

Southampton Solent University,

East Park Terrace,

Southampton

Hampshire,

SO14 0YN

Telephone: 02382016465

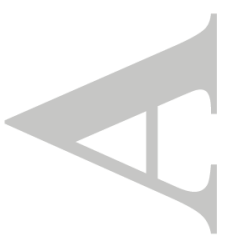

This article has been accepted for publication and undergone full peer review but has not been through the copyediting, typesetting, pagination and proofreading process which may lead to differences between this version and the Version of Record. Please cite this article as an 'Accepted Article', doi: 10.1002/mus.25557 
Abstract word count: 150

Manuscript word count: 3392

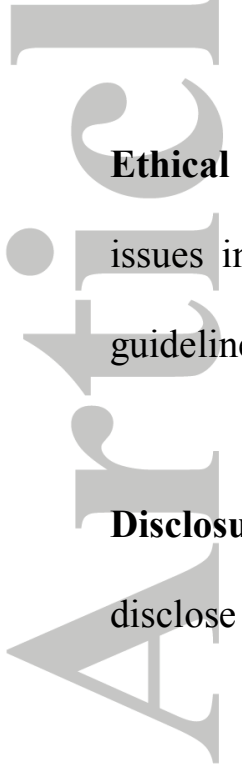

Keywords: Repetition maximum; Momentary failure; Intensity; Effort; Muscle; Strength

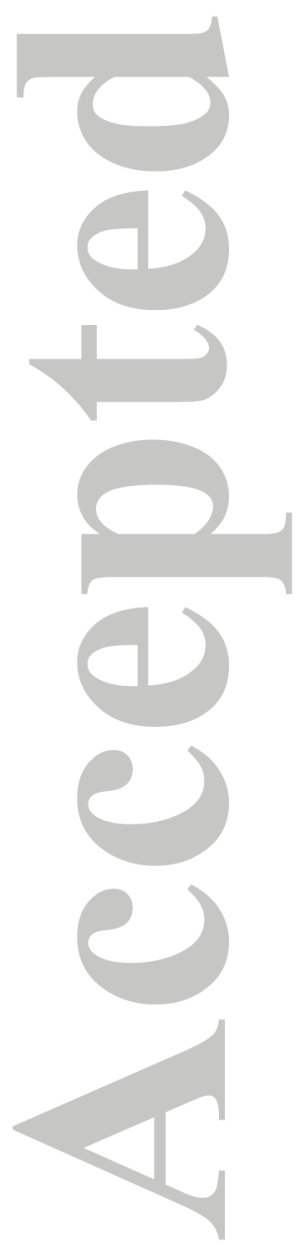

John Wiley \& Sons, Inc.

This article is protected by copyright. All rights reserved. 


\section{$\underline{\text { Abstract }}$}

Prior resistance training (RT) recommendations and position stands have discussed variables that can be manipulated when producing RT interventions. However, one variable that has received little discussion is set end points (i.e. the end point of a set of repetitions). Set end points in RT are often considered to be proximity to momentary failure and are thought to be a primary variable determining effort in RT. Further, there has been ambiguity in use and definition of terminology that has created issues in interpretation of research findings. The purpose of this paper is to: 1) provide an overview of the ambiguity in historical terminology around set end points; 2) propose a clearer set of definitions related to set end points; and 3) highlight the issues created by poor terminology and definitions. It is hoped this might permit greater clarity in reporting, interpretation, and application of RT interventions for researchers

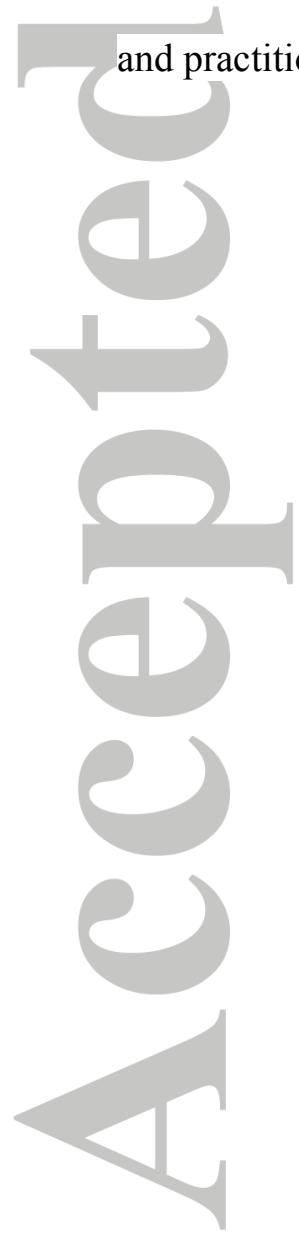




\section{Introduction}

The American Colleague of Sports Medicine (ACSM) has published numerous position stands regarding recommendations for application of resistance training (RT) [1,2]. These highlight a number of variables that can be manipulated when producing RT interventions. However, a variable that has received little discussion in these position stands was that of set end points (i.e. the end point of a set of repetitions). Repetition ranges were offered (i.e. performance of 8-12 repetitions), indicating voluntary set end points might include the performance of a predetermined number of repetitions. However, the discussion of whether or not any other particular criteria should be met in addition to achieving a set repetition number was absent. Others have considered set end points further with reference to proximity to momentary failure (MF), defined most recently as "the inability to perform anymore concentric contractions without significant change to posture or repetitions duration" [3]. This definition suggests alteration to repetition duration is a factor to consider in determining whether MF has occurred. It should be noted that when repetitions are performed with maximal intended velocity, repetition duration can increase prior to, and leading to, MF being achieved $[4,5]$. Thus the definitions we offer later have removed this consideration. In essence, the most appropriate conceptualization of MF is that it occurs at the point where, despite the greatest effort, a person is unable to meet and overcome the demands of the exercise causing an involuntary set end point.

Most research considers people training 'to MF' or 'not to MF' or in some cases what has been referred to as "past MF" (the use of advanced RT techniques such as drop sets, restpause, forced reps to enable a trainee to continue repetitions after achieving MF). Recent reviews which have considered this variable have in fact employed the distinction of "to MF" or "not to MF" in reviewing the literature regarding the impact of training to MF [3,6-8]. 
Following this, proximity to MF has been considered an indicator of the effort employed during RT. In fact the suggestion has being made that, due to inter- and intra-individual variations in number of repetitions possible prior to MF at the same relative loadings, if the intention is to match inter- and intra-individual effort, the only way to objectively do so is to have people train to MF (i.e. maximal effort $[3,10]$ ). Further, some propose that effort could also relate to intended velocity during RT, with maximal intended velocity related to maximal effort [9]. However, it would appear that velocity produced when it is intended to be maximal may in fact better serve as a an indicator of the degree of fatigue prior to reaching MF. It has been shown that velocity correlates well with other physiological markers of fatigue in a dose-response fashion to the number of repetitions performed relative to the number possible (i.e. number prior to reaching $\mathrm{MF}[4,5])$.

More recently, it has been argued that MF should be used as the means to standardize the RT stimulus [11]. We do not wish to suggest that persons should always train to MF, however if in a research or practical setting it is desirable to control effort objectively, it might be applied. For example, when comparing another independent RT variable between intervention arms in research, effort should be matched. Also it may be desirable to ensure that an athlete is working to the same relative effort (i.e. maximal by training to MF or if submaximal by first determining their repetitions to MF to then determine number of repetitions required to approximate the relative effort desired) as another, or on each exercise used in a training program.

A number of recent reviews have offered the conclusion that training to MF may confer greater adaptations in strength [3], hypertrophy [8], and possibly cardiorespiratory fitness [7]. Conversely, other recent studies have reported contrasting results regarding the efficacy of 
training to MF [12-15]. Considering the contrasting findings in the literature, it is important to investigate the role of effort further, as determined by set end point criteria in determining adaptations from RT. However, consideration of a trichotomous nature to set end points (to $\mathrm{MF}$, not to MF, or continuation of repetitions after MF through use of advanced techniques) limits the degree to which it is possible to fully understand the relationship of intensity of effort to RT adaptations. For example the dose-response nature of differing intensities of effort is unknown in addition to whether a threshold of relative effort exists to optimize adaptations. Investigation of this is further confounded by issues in interpreting previous research due to vague definitions and practical application of terms such as 'repetition maximum' (RM [16-17]). As detailed below, RM is often used synonymously with MF, or a definition is not provided by authors reporting it. Examination of this ambiguity supports the need for greater clarity in terminology and definition in future RT research, both for examining the role of intensity of effort and in choosing appropriate control of this variable when other independent variables are being examined.

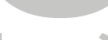

Thus the purpose of this paper is as follows: 1) provide an overview of the ambiguity in historical definitions of terms related to set end points including RM and 'momentary muscular failure'; 2) propose a set of definitions that permit researchers and practitioners greater clarity in reporting, interpreting, and applying RT interventions; and 3) highlight the issues created by the application of the contrasting prior historical definitions with respect to interpreting what has actually occurred in an RT intervention.

\section{Historical Definitions}

Classic papers in addition to current textbooks in RT and exercise physiology provide a range of terms and definitions of RM and MF. In many cases, there are discrepancies in the exact 
definitions for the same term. In particular there are instances where it is difficult to distinguish between definitions of RM and MF. Table 1 provides examples where the term RM has been defined. Table 2 provides examples where the term MF has been defined. Though this is not an exhaustive list, perusal of the definitions in the 2 tables should make it clear that in some cases it is difficult to distinguish between RM and MF. There is no clear delineation between the 2 terms which could be easily achieved by considering the success (RM) or failure (MF) to complete the final repetition on which set ends. Readers will note that 2 terms appear to be used interchangeably in the literature. Indeed in at least some cases the 2 terms have been used seemingly interchangeably by the same authors at different points in their texts [18-19]. It should also be noted that the ascription of intensity of effort to each of these definitions also differs among authors, as some have stated that maximal effort is required and others have not. There is also considerable ambiguity in the use of the terms fatigue and failure in defining the terms.

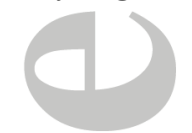

Further, it is not uncommon for many authors to use an array of similar terminology including muscular failure, muscular fatigue, or volitional exhaustion without offering any definition of these terms [26]. This seems to imply that these terms and their definitions are commonly accepted in the RT literature. Indeed many of the definitions in the above tables have been termed similarly in their original sources. However, as can be seen from tables 1 and 2 , the assumption that these terms and their definitions are commonly accepted would appear to be false.

\section{Definitions of Set End Points}

In an attempt to rectify this ambiguity and to provide wider consideration of the role of intensity of effort in RT, Giessing et al. [16] have proposed 4 definitions of set end points, 
providing a gradient of intensity of effort during RT; non-repetition maximum, repetition maximum, point of momentary failure, point of momentary failure plus advanced techniques (e.g. drop sets, rest pause, forced repetitions). We have expanded and added to these definitions for the purpose of this article to also include self-determined repetition maximum (Table 3). Further, though the term 'repetition failure' has been used recently [14] we have opted to use the term 'momentary failure', as 'repetition failure' might be thought to apply predominantly to dynamic training modalities involving concentric and eccentric contractions. However, the definition of MF offered here, if it were considered that MF was failure to meet the demands of the exercise, could be expanded to also include predominantly isometric and eccentric RT. For example, if holding an isometric contraction the point where, despite attempting to maintain the current position, the subject cannot prevent an eccentric contraction from occurring. Or if performing eccentric-only repetitions with a prescribed repetition duration the point where, despite attempting to maintain the prescribed repetition duration, the subject cannot prevent the eccentric contraction from occurring at a shorter repetition duration than prescribed.

Historically the primary ambiguity in the RT literature regarding definition of set end points has been that of RM and its relation to MF. Giessing et al. [16] differentiated between the 2 as follows:

"The difference between the RM and the point of MF is that the RM means that the set is terminated after the final repetition has been completed [authors' emphasis] in good form... whereas the point of MF means that once the RM has been reached another repetition is attempted [authors' emphasis] but not completed. Therefore the last repetition is the failed repetition." 
Considering the definitions in table 3 it is clear to see that determination of a true RM requires prior load determination and knowledge of the possible number of repetitions that a trainee can perform to MF at that load in order to determine the number of repetitions for an RM. RM is thus best described as the number of complete repetitions prior to MF. Should the exercise be ended once trainees determine they could not complete further repetitions if attempted (i.e. they predict MF on the next repetition), this might be considered volitional or self-determined $R M(\mathrm{sdRM})$, not a true $\mathrm{RM}$, and thus it is a practical yet somewhat ambiguous set end point definition. Considering this, RM is only included here for comparative purposes, as from an applied standpoint the use of true RM as a set end point criterion seems impractical. A key feature here of the definition of MF is that, when trainees attempt to reach MF they should, subsequent to completing a repetition, attempt the following repetition until they actually fail to complete one. Without actually attempting a subsequent repetition upon completion of each prior repetition, it is impossible to be certain that a person has in fact reached MF or indeed will do so on the subsequent repetition. This distinction is particularly important, as numerous studies report having had participants train to an RM which is often interpreted as synonymous with MF [6,7]. Indeed, if we consider prior historical definitions of the 2 , it would appear that such an interpretation may not be accurate. Thus it is often unclear whether people have trained to an RM, or if they have in fact trained to MF, as we have defined here (Table 3). Some of the historical ambiguity may arise from conflation of interpretation and application of the term RM for testing purposes and for training loads. The load obtained in an RM test (or MF) may differ from day to day and depend upon a number of inter- and intra-individual variables (28). Thus the application to training of an absolute 'RM' load obtained from testing may or may not be appropriate to meet recommendations from session to session. 
It is important also to note here the differentiation between failure and fatigue. We have included the definition of MF+ being that failure occurs at a point where trainees, despite giving a maximal effort, can no longer meet the demands of the task. Yet, if the demands were reduced they could continue. Fatigue, conversely is best defined as " $a$ transient decrease in the capacity to perform physical actions" [29, pp 11]. Thus it is an ongoing process during RT which may or may not result in failure. For example, during a set of repetitions performed to $\mathrm{MF}$ as consequent repetitions are performed, trainees fatigue and require greater degrees of effort until they either stop at a predetermined repetition number or finally reach MF and are putting forth a maximal effort. Indeed from repetition to repetition it has been shown that power output decreases during a set to MF [30]. In the case of MF+ (i.e. use of advanced techniques to continue repetitions after MF) the load could further be reduced at this point (drop set), assistance provided (forced repetitions), or a brief pause permitted (rest-pause), and trainees continue perform repetitions due to the decreased demands and are not maximally fatigued. However, effort initially is not maximal but reaches max should trainees subsequently reach MF again. Thus it is apparent that it is not necessarily accurate to say that maximal fatigue or exhaustion has occurred upon reaching failure [6,31], though at least some degree of fatigue will have inevitably occurred.

In our definitions we have anchored intensity of effort as being maximal at the point of MF. This is partly due to the reasoning given above regarding differentiation of fatigue and failure. However, we believe this is also necessary due to the apparent difficulty people experience in differentiating between perceptions of effort and discomfort. A recent review [32] has discussed the differentiation between what is termed effort, defined as "the amount of mental or physical energy being given to a task", and exertion defined as "the amount of 
heaviness and strain experienced in physical work". The authors of this review noted that both terms are often used interchangeably and in certain languages can translate as synonyms.

Further, discomfort has also been used previously to describe the physiological and unpleasant sensations associated with exercise [33]. Thus, for this reason here we have opted to use the term discomfort as opposed to exertion. Differentiation between perceptions of effort and discomfort have been highlighted recently as important [32,33], particularly in RT [10] for good reason. A number of studies [34-38] measuring rating of perceived exertion (RPE) using a Borg CR10 scale [39] (where a value of 10 indicates maximal effort) have reported that participants exercised to $\mathrm{MF}$ and received verbal encouragement to ensure adequate motivation and effort. In this case, each trial, irrespective of exercise, load, or training status should have resulted in a maximal value for effort, since people were exercising to MF. Though those studies which have compared training to MF with training not to MF show that RPE for the active muscle is indeed higher when training to MF $[37,38]$, maximal values (e.g. a score of 10) were not reported in any of the studies cited. Thus we can only assume that the participants were unclear as to how to report their perception of effort.

Increasing ratings of effort were, however given with conditions known anecdotally to produce greater acute discomfort such as lower load lower body exercise [34], as set volumes increased [36], with increased work volume [35], and with increased work rate [37,38]. This suggests participants more likely expressed their feelings of increasing discomfort [10,40]. If persons are inappropriately anchoring their perceptions of effort upon feelings of discomfort, they may be likely to end their sets further from the point of MF than expected if they were using RM or self-determined RM as a set end point. Perceived effort is likely centrally mediated, whereas perceptions of discomfort may be more closely associated with afferent feedback [33]. This is particularly important to consider when using different loading schemes due to the different fatigue processes involved at different loads (i.e. during high 
load failure occurs due to central fatigue compared with peripheral neuromuscular fatigue during lower loads [41]). During low loads, peripheral fatigue processes produce greater increases in inorganic phosphate $\left(\mathrm{P}_{\mathrm{i}}\right)$ along with increases in $\mathrm{H}+$, to decrease intramuscular $\mathrm{pH}$ and potentially affect afferent feedback and perceived discomfort [42-44]. Thus the differentiation of effort from discomfort, and the anchoring of maximal effort as being synonymous with MF, provides a point from which to examine the role of differing intensities of perceived effort during submaximal efforts. This might permit further understanding of the dose-response role of perceived effort during RT.

The need for clear terminology and definitions is also evident when attempting to understand the interaction that variables such as set end point, and thus effort, have with other RT variables. For example, broad recommendations for specific repetition ranges using specific relative loadings may be inherently flawed. The number of possible repetitions varies between individuals based on training status and even within individuals for different exercises [34,45]; for example using a load of $80 \% 1 \mathrm{RM}$, an individual may fail during the nineteenth repetition attempted using a leg press, yet during the seventh repetition attempted for knee flexion. In this example a recommendation to perform 8-12 repetitions using that relative load would result in 1 exercise requiring relatively low effort, while the other would result in maximal effort yet be impossible to accomplish (i.e. result in MF). A further issue is the interpretation of the application of training to MF when studies have utilized multiple set RT protocols [46]. It may have been reported that participants trained to MF in all sets. Yet, when combined with specific repetition range recommendations, it has been shown that loading and/or rest intervals require manipulation from set to set in order to maintain individual ability to achieve the specified repetition range due to fatigue from earlier sets [4751]. Unless described carefully it is often difficult to interpret whether participants trained to 
MF or not, and if not, the proximity to MF they achieved (46). This point bears important implications regarding both control of effort in addition to the relative loadings being used, which researchers and practitioners should consider. Ultimately it is important that clear terms and careful definitions are used when reporting on RT interventions if we are to gain the greatest understanding of the application of differing manipulations of RT variables $[52,53]$.

\section{Conclusions and Directions for Future Research}

In combination with the definitions outlined here, researchers and practitioners might consider using tools that allow participants to differentiate between, and report individually, perceived effort and discomfort. This might allow researchers to examine the relationship between perceptions of effort during submaximal RT and subsequent adaptation. A recent study has already employed 2 of the definitions offered here in order to differentiate between and compare practical applications of set end points, in this case self-determined RM compared to MF under load volume matched conditions [12]. This study offered insight into the role of effort in determining adaptations in trained people. We believe that application and reporting of these definitions will assist in future research designs to fully elucidate the role of intensity of effort in RT. By using the point of MF as an anchor for maximal effort, future research designs might better determine the role that different intensities of effort along a gradient play in determining adaptations. Indeed, research designs might utilize submaximal effort repetition cessation criteria (nRM or $\mathrm{sdRM}$ ) which, although representing practically applicable definitions, represent situations whereby the degree of perceived effort may differ between people due to the differing proximities to MF that participants reach. Future research using tools to differentiate effort and discomfort in combination with these definitions might also permit better examination of the validity and efficacy of using 
subjective perceptions of effort to direct RT using practically applicable set end point criteria in different populations. We have begun to examine these areas in our lab [54,55]. Of course, we should note that even training to MF could be considered in some way subjective and as such we have clarified in our definition that trainees should consider this as a set end point only when they cannot complete the repetition despite attempting to do so.

(1)

To conclude, we hope that we have highlighted the issue associated with ambiguous historical terminology and definitions of set end points. Further, we believe the terminology and definitions presented here offer practically applicable set end point criteria that would allow researchers and practitioners to report, interpret, and apply RT interventions with greater clarity. It is recommended that future RT literature utilize this terminology, or at the least offer an accurate definition of what repetition cessation criteria are being used. This will ensure a better understanding of exactly what was done or is being proposed.

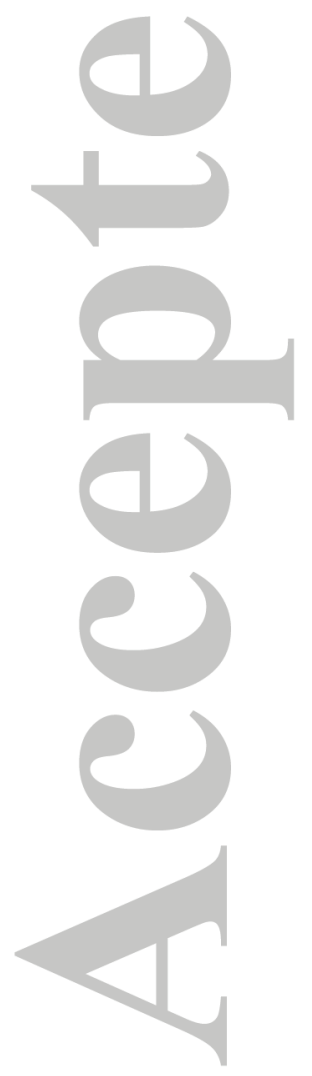

John Wiley \& Sons, Inc.

This article is protected by copyright. All rights reserved. 


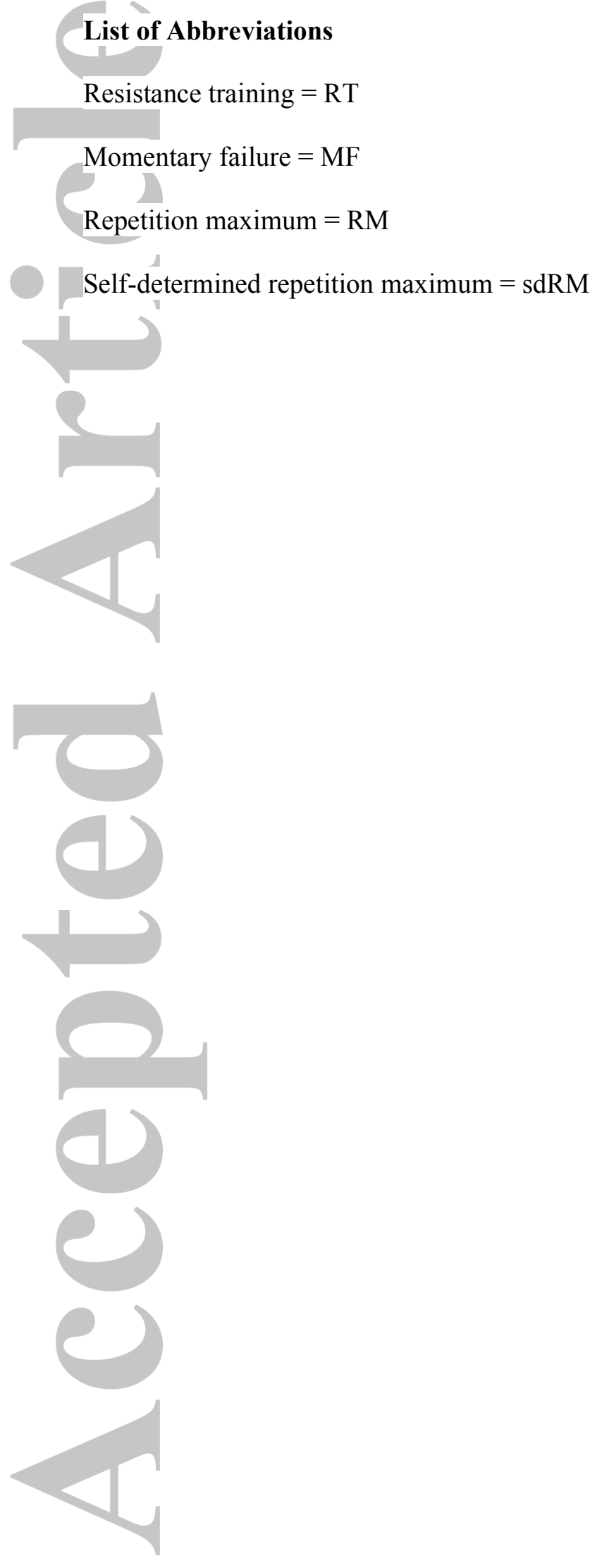

John Wiley \& Sons, Inc.

This article is protected by copyright. All rights reserved. 


\section{References}

1. Kraemer, WJ, Adams, K, Cafarelli, E, Dudley, GA, Dooly, C, Feigenbaum, et al. American College of Sports Medicine position stand. Progression models in resistance training for healthy adults. Med Sci Sports Exerc 2002; 34(2): 364 - 380

2. Ratamess, NA, Alvar, BA, Evotoch, TK, Housh, TJ, Kibler, WB, Kraemer, WJ, et al. American College of Sports Medicine position stand. Progression models in resistance training for healthy adults. Med Sci Sports Exerc 2009; 41(3): 687 - 708

3. Fisher, J, Steele, J, Smith, J, Bruce-Low, S. Evidence based resistance training recommendations. Medicina Sportiva 2011; 15(3): 147- 162

4. Izquierdo, M, Gonzalez-Badillo, JJ, Hakkinen, K, Ibanez, J, Kraemer, WJ, Altadil, A, et al. Effect of loading on unintentional lifting velocity declines during single sets of repetitions to failure during upper and lower extremity muscle actions. Int J Sports Med 2006; 27(9): $718-724$

5. Sanchez-Medina, L, Gonzalez-Badillo, JJ. Velocity loss as an indicator of neuromuscular fatigue during resistance training. Med Sci Sports Exerc 2011; 43(9): $1725-1734$

6. Willardson, JM. The application of training to failure in periodized multiple-set resistance exercise training programs. J Strength Cond Res 2007; 21(2): 628 - 631

7. Steele, J, Fisher, J, McGuff, D, Bruce-Low, S, Smith, D. Resistance training to momentary muscular failure improves cardiovascular fitness in humans: a review of acute physiological responses and chronic physiological adaptations. J Exerc Physiol online 2012; 15(3): $53-80$

8. Fisher, J, Steele, J, Smith, D. Evidence-based resistance training recommendations for muscular hypertrophy. Medicina Sportiva 2013; 7(4): 217 - 235 
9. Gonzalez-Badilllo, JJ, Marques, MC, Sanchez-Medina, LS. The importance of movement velocity as a measure to control resistance training intensity. J Hum Kinet 2011; 29A: 15-19

10. Steele, J. Intensity; in-ten-si-ty; noun. 1. Often used ambiguously within resistance training. 2. Is it time to drop the term altogether? Br J Sports Med 2014; 48(22): 1586 $-1588$

11. Dankel, SJ, Jesse, MB, Mattocks, KT, Mouser, JG, Counts, BR, Buckner, SL, et al. Training to fatigue: The answer for standardisation when assessing muscle hypertrophy? Sports Med 2016; Epub ahead of print

12. Giessing, J, Fisher, J, Steele, J, Rothe, F, Raubold, K, Eichmann, B. The effects of low volume resistance training with and without advanced techniques in trained participants. J Sports Med Phys Fitness 2016; 56(3): 249-258

13. Izquierdo-Gabarren, M, Gonzalez De Txbarri Exposito, R, Garcia-pallares, J, Sanchez-medina, J, De Villarreal, ES, Izquierdo, M. Concurrent endurance and strength training not to failure optimises performance gains. Med Sci Sports Exerc 2010; 42(6): $1191-1199$

14. Sampson, JA, Groeller, H. Is repetition failure critical for the development of muscle hypertrophy and strength? Scand J Med Sci Sports 2016; 26(4):375-383

15. Fisher, JP, Blossom, D, Steele, J. A comparison of volume equated knee extensions to failure, or not to failure, upon rating of perceived exertion and strength adaptations. Appl Physiol Nutr Metabol 2016; 41(2): 168-174

16. Giessing, J, Preuss, P, Greiwing, A, Goebel, S, Muller, A, Schischek, A, et al. Fundamental definitions of decisive training parameters of single-set training and multiple-set training for muscle hypertrophy. In: Giessing, J, Froehlich, M, Preuss, P. 
eds: Current Results of Strength Training Research. Goettingen: Cuvillier; 2005, 9 23

17. Giessing, J. How intense are your weight training workouts? NSCA's Performance Training J 2007; 6(1): $11-13$

18. Fleck, SJ, Kraemer WJ. Designing Resistance Training Programs. Champaign, IL: Human Kinetics; 2004, 5 - 196

19. Zatsiorsky, VM, Kraemer, WJ. Science and Practice of Strength Training. Champaign, IL: Human Kinetics; 2006, 71 - 82

20. DeLorme, TL. Restoration of muscle power by heavy-resistance exercises. J Bone Joint Surg Am 1945; 27(4): 645 - 667

21. DeLorme, TL, Watkins, AL. Technics of progressive resistance exercise. Arch Phys Med Rehabil 1948; 29(5): $263-273$

22. Astrand, PO, Rodahl, K, Dahl, HA, Stromme, SB. Textbook of Work Physiology: Physiological Bases of Exercise. Champaign, IL: Human Kinetics; 2003, 320

23. Wilmore, JH, Costill, DL. Physiology of Sport and Exercise. Champaign, IL: Human Kinetics; 200487 - 107

24. Baechle, TR, Earle, RW, Wathen, D. Resistance training. In: Baechle, TR, Earle RW eds: Essentials of Strength and Conditioning. Champaign, IL: Human Kinetics; 2008, 394

25. Bompa, TO, Di Pasquale, MG, Cornacchia, L. Serious Strength Training. Champaign, IL: Human Kinetics; 2013, 234

26. Carpinelli, RN. A critical analysis of the claims for inter-set rest intervals, endogenous hormonal responses, sequence of exercise, and pre-exhaustion exercise for optimal strength gains in resistance training. Medicina Sportiva 2010; 14(3): $126-$ 156

John Wiley \& Sons, Inc. 
27. Willardson, JM, Norton, L, Wilson, G. Training to failure and beyond in mainstream resistance exercise programs. Strength Cond J 2010; 32(3): 21-29

28. Steele, J. Re: Dichotomy in translation raises the need for careful definition in use. $\mathrm{Br}$ J Sports Med 2015; e-letter, http://bjsm.bmj.com/content/48/22/1586.extract/reply

29. Enoka, RM, Duchateau, J. Muscle fatigue: what, why and how it influences muscle function. J Physiol 2008; 586(1): 11-23

30. Drinkwater, EJ, Galna, B, McKenna, MJ, Hunt, PH, Pyne, DB. Validation of an optical encoder during free weight resistance movements and analysis of bench press sticking point power during fatigue. J Strength Cond Res 2007; 21(2): 51 - 517

31. Drinkwater, EJ, Lawton, TW, Lindsell, RP, Pyne, DB, Hunt, PH, McKenna, MJ. Training leading to repetition failure enhances bench press strength gains in elite junior athletes. J Strength Cond Res 2005; 19(2): 382 - 388

32. Abbiss, CR, Peiffer, JJ, Meeusen, R, Skorski, S. Role of ratings of perceived exertion during self-paced exercise: What are we actually measuring? Sports Med 2015; 45: $1235-1243$

33. Marcora, S. Perception of effort during exercise is independent of afferent feedback from skeletal muscles, heart, and lungs. J Appl Physiol 2009; 106: 2060 - 2062

34. Shimano, T, Kraemer, WJ, Spiering, BA, Volek, JS, Hatfield, DL, Silvestre, R, et al. Relationship between the number of repetitions and selected percentages of one repetition maximum in free weight exercises in trained and untrained men. J Strength Cond Res 2006; 20: $819-823$

35. Pritchett, RC, Green, JM, Wickwire, PJ, Pritchett, KL, Kovacs, MS. Acute and session RPE responses during resistance training: Bouts to failure at $60 \%$ and $90 \%$ of 1RM. SAJSM 2009; 21(1): $23-26$ 
36. Silva, VL, Azevedo, AP, Cordeiro, JP, Duncan MJ, Cholewa, JM, Siqueira-Filho, MA, et al. Effects of exercise intensity on perceived exertion during multiple sets of bench press to volitional failure. J Trainol 2014; 3: 41 - 46

37. Hiscock, DJ, Dawson, B, Donnelly, CJ, Peeling, P. Muscle activation, blood lactate, and perceived exertion responses to changing resistance training programming variables. Eur J Sport Sci 2015; 16(5): 536-544

38. Hiscock, DJ, Dawson, B, Peeling, P. Perceived exertion responses to changing resistance training programming variables. J Strength Cond Res 2015; 29(6): 15641569

39. Borg, GA. Psychophysical bases of perceived exertion. Med Sci Sports Exerc 1982; 14: $377-381$

40. Smirnaul, BDC. Sense of effort and other unpleasant sensations during exercise: clarifying concepts and mechanisms. Br J Sports Med 2012; 46: 308 - 311

41. Behm, DG, Reardon, G, Fitzgerald, J, Drinkwater, E. The effect of 5, 10, and 20 repetitions maximums on the recovery of voluntary and evoked contractile properties. J Strength Cond Res 2002; 16(2):209-218.

42. Schott, J, McCully, K, Rutherford, OM. The role of metabolites in strength training II. Short versus long isometric contractions. Eur J Appl Physiol 1995;71: 337-341.

43. Takarada, S, Okita, K, Suga, T, Omokawa, M, Kadoguchi, T, Sato, T, et al. Lowintensity exercise can increase muscle mass and strength proportionally to enhance metabolic stress under ischemic conditions. J Appl Physiol 2012; 113:199-205.

44. MacDougall, JD, Ray, S, Sale, DG, McCartney, N, Lee, P, Garner, S. Muscle substrate utilization and lactate production during weight lifting. Can J Appl Physiol 1999; 24(3):209-215. 
45. Hoeger, WWK, Hopkins, DR, Barette, SL, Hale, DF. Relationship between repetitions and selected percentages of one repetitions maximum: A comparison between untrained and trained males and females. J Strength Cond Res 1990; 4(2): 46-54

46. Gentil, P, Steele, J, Fisher, J, Arruda, A. Manuscript clarification: Dose-Response of 1, 3, and 5 Sets of Resistance Exercise on Strength, Local Muscular Endurance, and Hypertrophy. J Strength Cond Res 2015; E-pub ahead of print

47. Willardson, JM, Burkettt, LN. A comparison of 3 different rest intervals on the exercise volume completed during a workout. J Strength Cond Res 2005; 19(1): 23-26

48. Willardson, JM, Burkettt, LN. The effect of rest interval length on bench press performance with heavy vs. light loads. J Strength Cond Res 2006; 20(2): 396-399

49. Willardson, JM, Burkettt, LN. The effect of rest interval length on the sustainability of squat and bench press repetitions. J Strength Cond Res 2006; 20(2): 400-403

50. Willardson, JM, Simao, R, Fontana, FE. The effect of load reductions on repetitions performance for commonly performed multi-joint resistance exercises. J Strength Cond Res 2012; 26(11): 2939-2945

51. Richmond, SR, Godard, MP. The effects of varied rest periods between sets to failure using the bench press in recreationally trained men. J Strength Cond Res 18(4): 846849, 2004

52. Paoli, A. Resistance training: The multifaceted side of exercise. Am J Physiol Endocrinol Metab 2012; 302(3): E387

53. Paoli, A, Bianco, A. Not all exercises are created equal. Am J Cardiol 2012; 109(2): 305

54. Steele, J, Fisher, J, McKinnon, S, McKinnon, P. Differentiation between perceived effort and discomfort during resistance training in older adults: Reliability of trainee 
ratings of effort and discomfort, and reliability and validity of trainer ratings of trainee effort. J Trainol 2016; In press

55. Fisher, J, Ironside, M, Steele, J. Heavier- and lighter-load resistance training to momentary failure produce similar increases in strength with differing degrees of discomfort. Muscle Nerve; Epub ahead of print
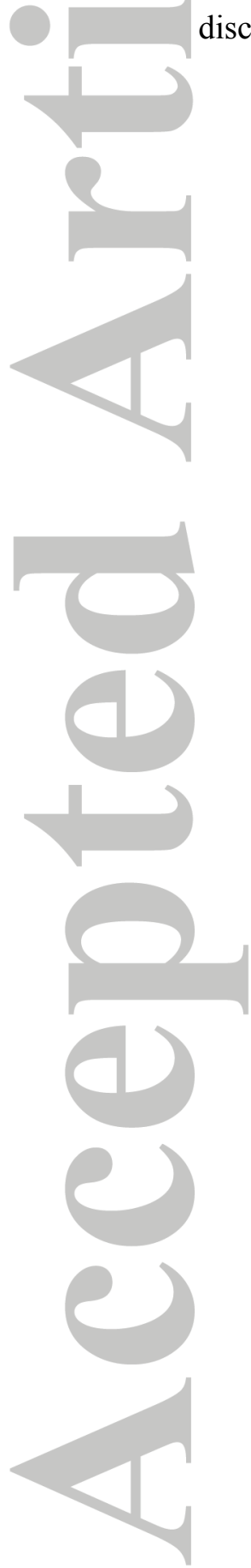

John Wiley \& Sons, Inc.

This article is protected by copyright. All rights reserved. 


\section{TABLES}

Table 1. Examples of previous definitions of 'Repetition Maximum'

Reference
DeLorme, 1945, pp 648 (20)
DeLorme \& Watkins, 1948, pp 264 (21)

Astrand et al., 2003, pp 320 (22)

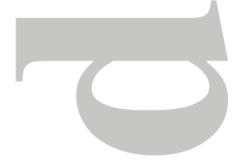

Wilmore \& Costill, 2004, pp 87 (23)

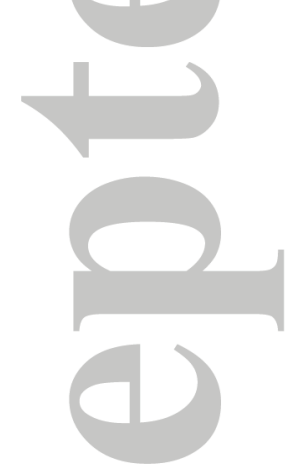

ibid, pp 107 (23)

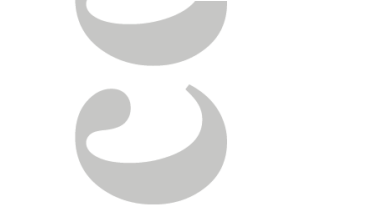

Fleck \& Kraemer, 2004, pp 5 (18)
In reference to the ten-repetition maximum "That weight which requires maximum exertion to perform ten repetitions..."

"The 10 repetition maximum is the most weight that can be lifted correctly through a full arc of motion for 10 repetitions."

"When training with weights in dynamic contractions, one talks about nRM load. Which is the number of repetitions maximum. The weight is so chosen that it can be lifted $n$ times in good style, but is too heavy to lift $n+1$ times."

“...1-repetition maximum, or $1 R M$. To determine your $1 R M$ select a weight you know you can lift just once. After a proper warm-up, try to execute several repetitions. If you can perform more than one repetition, add weight and try again to execute several repetitions. Continue doing this until you are unable to lift the weight more than a single repetition."

"In contrast a 25RM load (i.e. the peak resistance that can be lifted only 25 times before reaching fatigue)..."

"A repetition maximum or $R M$ is the maximal number of repetitions per set that can be performed with proper lifting technique using a given resistance. Thus, a set at a certain RM implies that the set is performed to momentary voluntary fatigue.

John Wiley \& Sons, Inc. 


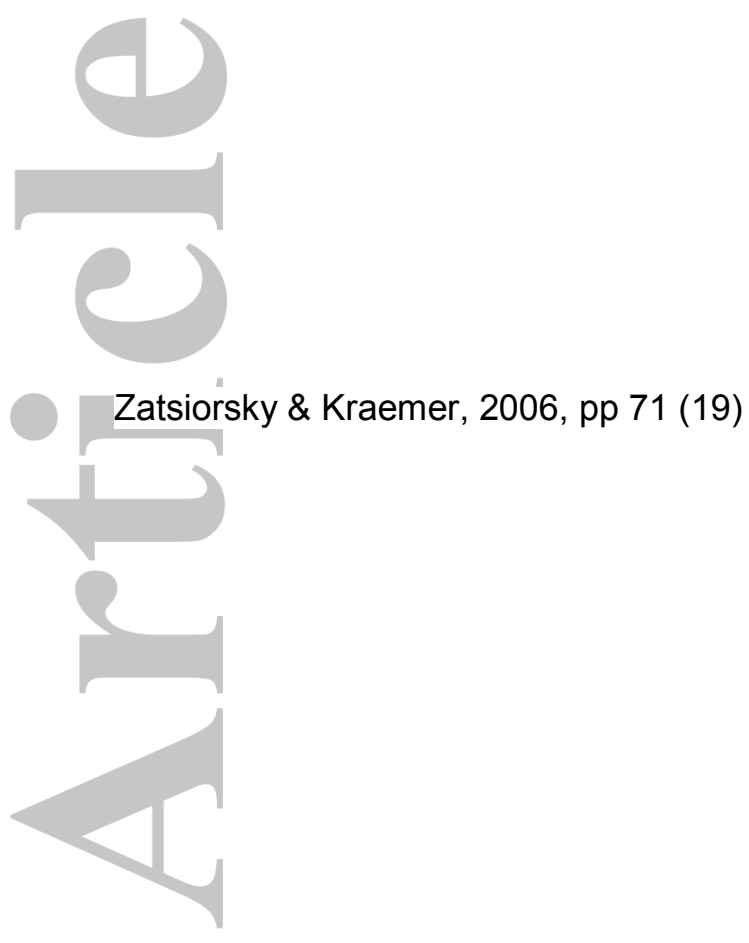

Baechle et al., 2008, pp 394 (24)

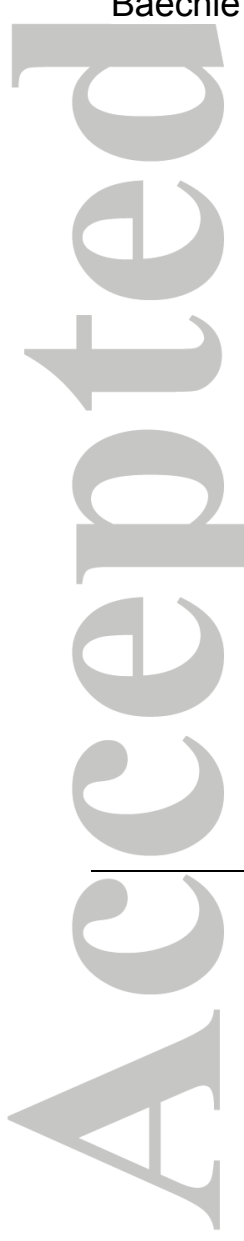

The heaviest resistance that can be used for 1 complete repetition of an exercise is $1 R M$. A lighter resistance that allows completion of 10 , but not 11 , repetitions with proper technique is 10RM."

"The magnitude of resistance (weight, load) can be characterised by the ultimate number of repetitions possible in one set (to failure). The maximal load that can be lifted a given number of repetitions before fatigue is called repetition maximum (RM)...determining RM entails the use of trial and error to find the greatest amount of weight a trainee can lift a designated number of times."

"Load is commonly described as either a certain percentage of a 1-repetition maximum (1RM) - the greatest amount of weight that can be lifted with proper technique for only one repetition - or the most weight lifted for a specified number of repetitions, a repetition maximum (RM). For instance, if an athlete can perform 10 repetitions with $60 \mathrm{~kg}$ in the back squat exercise, her 10RM is 60kg. It is assumed that the athlete provided a maximal effort; if she has stopped at nine repetitions but could have performed one more, she would not have achieved a 10RM. Likewise, if she lifted $55 \mathrm{~kg}$ for 10 repetitions (but could have performed more), her true 10RM was not accurately assessed because she possibly could have lifted 60kg for 10 repetitions."

John Wiley \& Sons, Inc. 
Table 2. Examples of previous definitions of 'Momentary Failure'

\begin{tabular}{|c|c|}
\hline Reference & Definition \\
\hline Bompa et al. 2013, pp 234 (25) & $\begin{array}{l}\text { "The training objective with submaximal } \\
\text { loads is to contract muscles to exhaustion } \\
\text { in an effort to recruit all the muscle fibres. } \\
\text { As you 'rep-out' to exhaustion, muscle fibre } \\
\text { recruitment increases...To achieve optimal } \\
\text { training benefits, an athlete must perform } \\
\text { the greatest number of repetitions possible } \\
\text { during each set. Bodybuilders should } \\
\text { always reach the state of local muscular } \\
\text { exhaustion that prevents them from } \\
\text { performing one more repetition, even when } \\
\text { applying maximal force." }\end{array}$ \\
\hline Fleck \& Kraemer, 2004, pp 196 (18) & $\begin{array}{l}\text { "An exhaustion set is a set performed until } \\
\text { no further complete repetitions with good } \\
\text { exercise technique can be completed. } \\
\text { Synonymous with exhaustion sets are the } \\
\text { terms carrying sets to volitional fatigue, sets } \\
\text { to failure, and sets to concentric } \\
\text { failure...The use of a repetition maximum } \\
\text { (RM) or an RM training zone (i.e 4-6RM) in } \\
\text { a training program indicates that sets were } \\
\text { carried to exhaustion." }\end{array}$ \\
\hline rksy \& Kraemer, 2006, pp 82 (19) & $\begin{array}{l}\text { Describing 'submaximal effort' and } \\
\text { 'repeated effort' training using the example } \\
\text { of a person with a } 100 \mathrm{~kg} 1 \mathrm{RM}-\text { " Lift a load } \\
\text { smaller than } 100 \mathrm{~kg} \text {, perhaps } 75 \mathrm{~kg} \text {, either a } \\
\text { submaximal number of times (submaximal } \\
\text { effort method) or to failure (repeated effort } \\
\text { method)." }\end{array}$ \\
\hline oid, pp 82 (19) & $\begin{array}{l}\text { "Methods using submaximal versus } \\
\text { repeated efforts differ only in the number of } \\
\text { repetitions per set - intermediate in the first } \\
\text { case and maximal (to failure) in the } \\
\text { second." }\end{array}$ \\
\hline ardson, 2007, pp 628 (6) & $\begin{array}{l}\text { "Muscular failure can be defined as the } \\
\text { point during a resistance exercise set when } \\
\text { the muscles can no longer produce } \\
\text { sufficient force to control a given } \\
\text { load...Muscular failure usually occurs } \\
\text { during the concentric phase of a } \\
\text { repetition...Therefore, to describe a muscle } \\
\text { as being maximally fatigued at the point of } \\
\text { concentric failure is inaccurate because the } \\
\text { muscle is not entirely fatigued." }\end{array}$ \\
\hline
\end{tabular}

John Wiley \& Sons, Inc.

This article is protected by copyright. All rights reserved. 
Table 3. Terminology and definitions for set end points.

Repetition Cessation Terminology

Non-Repetition Maximum (nRM)

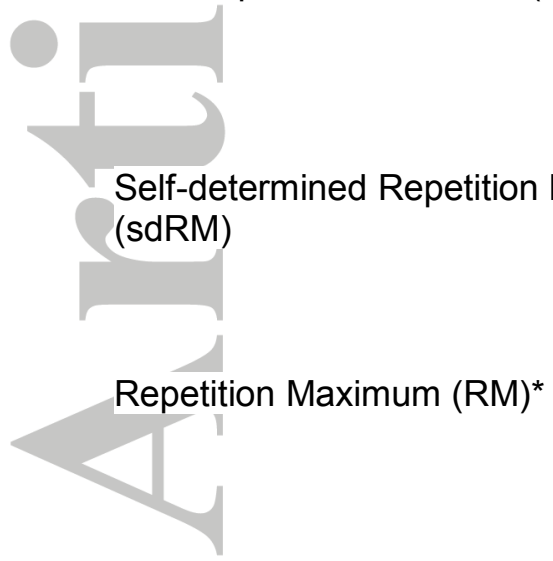

Momentary Failure (MF)

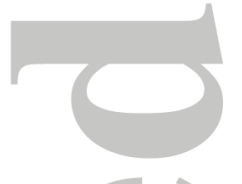

Momentary Failure Plus Advanced

Techniques [MF+(insert technique)]

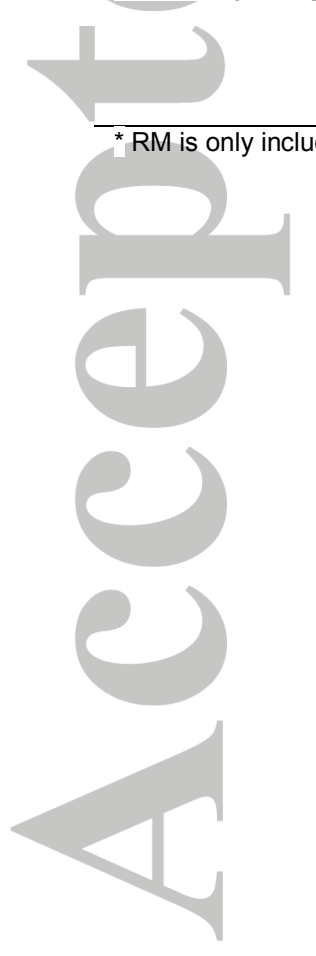

\section{Definition}

Set end point when trainees complete a pre-determined number of repetitions despite the fact that further repetitions could be completed.

Set end point when trainee determines they could not complete the next repetition if it were attempted (i.e. they predict MF on the following repetition).

Set end point when trainees complete the final repetition possible whereby if the next repetition was attempted they would definitely achieve MF.

Set end point when trainees reach the point where despite attempting to do so they cannot complete the concentric portion of their current repetition without deviation from the prescribed form of the exercise.

Set end point when trainees have completed a pre-determined advanced technique after already achieving MF (i.e. completion of forced/assisted repetitions, rest pause, drop sets)

John Wiley \& Sons, Inc.

This article is protected by copyright. All rights reserved. 